
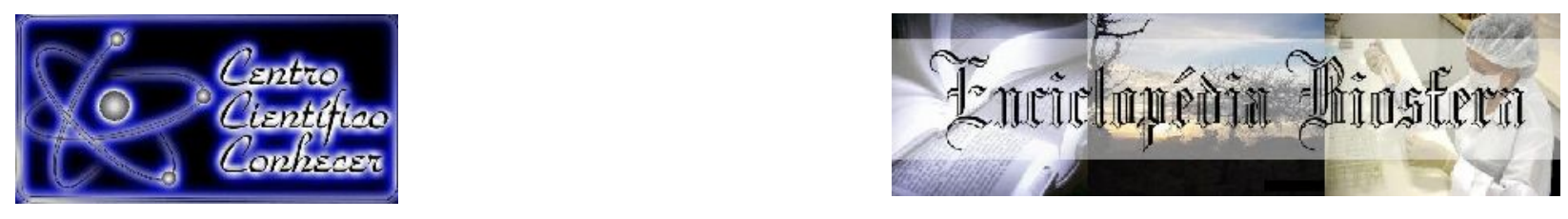

\title{
FATORES DE INFLUÊNCIA NA FORMAÇÃO DO PREÇO DOS HERBICIDAS À BASE DE GLIFOSATO NO BRASIL
}

\author{
Felipe Guimarães Facuri ${ }^{1}$, Michele Ribeiro Ramos ${ }^{2}$ \\ ${ }^{1}$ Aluno de Pós-Graduação (MBA) em Gestão de Negócios pela PECEGE- ESALQ \\ Piracicaba-SP, Brasil. \\ 2 Professora Doutora do Curso de Engenharia Agronômica da Universidade Estadual \\ do Tocantins, Palmas-TO, Brasil. Email: micheleribeiroramos2@gmail.com
}

Recebido em: 06/04/2019 - Aprovado em: 10/06/2019 - Publicado em: 30/06/2019 DOI: 10.18677/EnciBio_2019A71

\begin{abstract}
RESUMO
A molécula do glifosato está no mercado presente na formulação dos principais herbicidas a mais de quarenta anos, sendo considerado o produto mais utilizado no setor agropecuário. Esse trabalho, realizado por meio de relato de caso, mapeia e apresenta os aspectos que norteiam a formação de preço desses produtos no Brasil. Os fatores externos de maior influência mapeados foram: taxa do dólar, por impactar diretamente nas operações de importação e exportação, e também o preço do glifosato produzido na China, que é importante fornecedor para o mercado mundial e amplamente utilizado como matéria-prima dos produtos formulados no Brasil e como preço base para a formação dos preços finais em nosso país. Já os fatores internos, são considerados no processo de precificação: a demanda de mercado, que por meio do volume das safras e sazonalidade das mesmas oscilam períodos de alta e baixa demanda, os custos de produção, distribuição e venda de cada empresa e por último a intervenção governamental, que por gerar grande influência na taxação dos produtos importados, interfere nos custos e consequentemente na formação do preço dos herbicidas.
\end{abstract}

PALAVRAS-CHAVE: Análise conjunta, defensivos agrícolas, precificação.

\section{INFLUENCE FACTORS ON PRICE FORMATION OF GLYPHOSATE HERBICIDES IN BRAZIL}

\begin{abstract}
Glyphosate has been in the market for more than 40 years in the formulation of the highest consumption herbicides around the world is due to its importance for agriculture. This work, carried out through a case report, maps and presents the aspects that guide the price formation of these products in Brazil. The most influential external factors mapped were: dollar rate, for impacting directly on import and export operations, and also the price of glyphosate produced in China, which is an important supplier for the worldwide market and widely used As the raw material of the products formulated in Brazil and as a base price for the formation of the final prices in our country. The internal factors are considered in the pricing process: the market demand, which through the volume of the harvests and seasonality of them fluctuate periods of high and low demand, the costs of production, distribution and sale of
\end{abstract}


each company and lastly the Governmental intervention, which because it generates great influence on the taxing of imported products, interferes in costs and consequently in the formation of the price of the herbicides.

KEYWORDS: Conjoint analysis, pesticides, pricing of products and services

\section{INTRODUÇÃO}

Projeções realizadas pela Organização das Nações Unidas [ONU] mostram que a população global que em 2017 é de cerca de 7,6 bilhões de pessoas, atingirá 9,8 bilhões em 2050 e 11,2 bilhões em 2100 (ONU, 2018).

Com o aumento contínuo da população mundial, cresce também a demanda por alimentos e seu acesso em diferentes localidades do planeta, o que é essencial para um crescimento sustentável dessa população. No centro desse crescimento, a agricultura é a base e maior responsável pela produção e fornecimento de alimentos. De acordo com relatório da Organização para Cooperação e Desenvolvimento Econômico [OCDE] e da Organização das Nações Unidas para Agricultura e Alimentação [FAO], a produção agrícola e pesqueira no mundo terá um aumento na ordem de $20 \%$ entre os anos de 2018 e 2027 (OCDE-FAO, 2018).

O crescimento de tal magnitude na agricultura não seria possível sem o avanço contínuo da produtividade no campo, impulsionada pelo emprego de novas tecnologias em sementes, fertilizantes, defensivos e maquinário. Dentro do nicho dos defensivos, nos últimos 40 anos um dos agentes mais empregados no campo para controle de pragas, mais especificamente a eliminação de ervas daninhas, é o composto químico conhecido como Glifosato, ou N-fosfonometil glicina, vendido por muitos anos exclusivamente sobre a marca RoundUp® (OCDE-FAO, 2018). De acordo com dados do Instituto Mato-grossense de Economia Agropecuária (2018), os herbicidas representam cerca de $10 \%$ do total de despesas de custeio da lavoura em termos de insumos, ou $25 \%$ dentre os custos com defensivos, tomando como base uma fazenda de soja no estado do Mato Grosso na safra 2017/2018.

Desde o início do cultivo de lavouras, o homem enfrenta a tendência natural das diferentes espécies de plantas coexistirem e por muitas vezes competirem por água e nutrientes. Esse processo natural gera perda de produtividade (peso de alimento colhido vs. quantidade de terra e insumos utilizados) dessa plantação, especialmente em monoculturas. O controle de plantas daninhas sempre fora feito de maneira manual pelo agricultor, porém por volta da década de 1920 a utilização de dispositivos mecânicos era predominante, facilitando o controle dessas pragas, até que próximo da década de 1930 houve a concepção e aplicação em larga escala de meios de controle químico om o advento dos herbicidas (GALLI; MONTEZUMA, 2005).

$\mathrm{Na}$ década de 70 a Monsanto Company, empresa do ramo química, lança comercialmente o RoundUp®. Classificado como herbicida não-seletivo e de ação sistêmica, com largo espectro de ação. Por ser uma solução simples, com elevado custo benefício, e eficácia ao manter a lavoura sem o crescimento de plantas daninhas por um longo período, o Glifosato foi rapidamente adotado por diversas culturas ao redor do mundo (BUSINESSWIRE, 2017).

Em adição ao desempenho no campo, a importância dos herbicidas a base de glifosato, teve aumento considerável no mercado agrícola depois da criação de sementes geneticamente modificadas, as quais são resistentes ao mecanismo de funcionamento do RoundUp®. Dessa forma, em 1996 a Monsanto lança no mercado as sementes de soja com o selo "RoundUp Ready" [RR], gerando grande impacto no mercado com a venda não somente de produtos, mas a venda de uma solução para 
o agricultor. Não somente a Monsanto lucrara com tal descoberta, mas também suas concorrentes, como a também americana DuPont, compraram as patentes do gene resistente para produzir sementes $\mathrm{RR}$. Com isso, o consumo de glifosato aumentou de cerca 28 milhões de libras em 1995 para 185 milhões de libras em 2007, um expressivo aumento de $560 \%$ somente na aplicação agrícola (SUSTAINABLE PULSE, 2017).

O presente trabalho buscou mapear e descrever, mas não quantificar, os fatores internos e externos ao Brasil que possuem maior influência na formação do preço no mercado brasileiro dessa matéria-prima agrícola.

\section{MATERIAL E MÉTODOS}

O trabalho foi desenvolvido utilizando-se da escrita acadêmica no formato de relato de experiência, com informações obtidas pelos autores nos anos de 2017 e 2018 em sua experiência nas áreas de Marketing, Vendas e Inteligência de Mercado de uma empresa multinacional que atua no mercado brasileiro produzindo e comercializando, entre outros produtos de seu portfólio, herbicidas a base glifosato. Desse ponto em diante, para fins de confidencialidade, essa companhia será chamada de Empresa A.

Foram coletadas informações por meio de sessões de entrevistas com três profissionais, cada um representando as áreas de Marketing, Vendas e Inteligência de Mercado, sendo que todos eles atuam dentro da Empresa $A$, que serviu como base do estudo.

Os profissionais selecionados para as entrevistas foram indicados pela Empresa A por possuírem grande conhecimento sobre o tema, somando mais de 40 anos de experiência no mercado de agroquímicos e sementes transgênicas. Para guiar as entrevistas a fim de obter todas as informações necessárias, foi utilizado o roteiro de entrevistas. Após as entrevistas, de maneira complementar, o autor acompanhou parte da rotina de trabalho dessas áreas, onde foram coletadas informações internas e de relatórios comerciais/mercado fornecidos por empresas de pesquisas, e que foram adquiridos pela Empresa $A$.

\section{Mercado Atual e Projeções}

\section{RESULTADOS E DISCUSSÃO}

O mercado de produção de ingrediente ativo, formulação e venda de herbicidas a base de glifosato é uma cadeia complexa e fragmentada em diversas etapas. Sua produção passa por fases mais especializadas, como a produção dos intermediários (matérias-primas) e do ingrediente ativo, já outras são mais simples e estão mais pulverizadas em um maior número de "players", como na formulação e distribuição. Na Figura 1, são demonstradas as etapas principais de produção dos herbicidas.

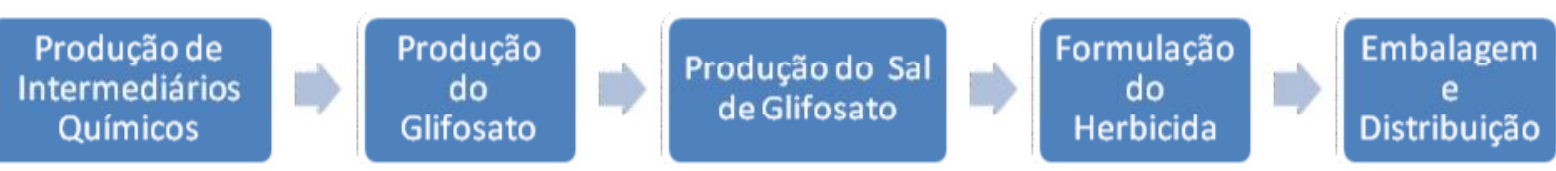

FIGURA 1. Esquema simplificado das principais etapas da cadeia de suprimentos dos herbicidas a base de glifosato

Fonte: Dados originais da pesquisa 
Em termos de tamanho de mercado, a comercialização de herbicidas a base de glifosato tem valor de US $\$ 6,51$ bilhões no ano de 2015 , o que é equivalente a uma produção de 800.000 toneladas ao ano, ao mesmo passo onde pesquisas mostram que esse mercado seguirá em um crescimento médio anual de $6,32 \%$, atingindo US\$ 9,91 bilhões no ano de 2022 (MARKETS; MARKETS, 2017).

O mercado é segmentado basicamente nas aplicações agrícolas, e para outras finalidades como jardinagem, por exemplo. No entanto, o setor agrícola representa a parcela de maior importância em termos de volume, conforme dados coletados por Benbrook (Figura 2).

Após a queda de patente no ano 2000, a Monsanto que era a única empresa na produção da molécula ativa e na formulação e venda dos herbicidas a base de glifosato perdeu "market share" para seus concorrentes. A produção do ativo por parte da Monsanto hoje sofre forte concorrência da indústria química chinesa, com uma divisão próxima de $50 \%$ para cada, isso devido a complexidade de sua produção. Enquanto isso, para os produtos formulados, a concorrência é mais dispersa, porém formada basicamente por matéria prima chinesa, enquanto a Monsanto continua a controlar sua produção e fornecimento do início ao fim da cadeia.

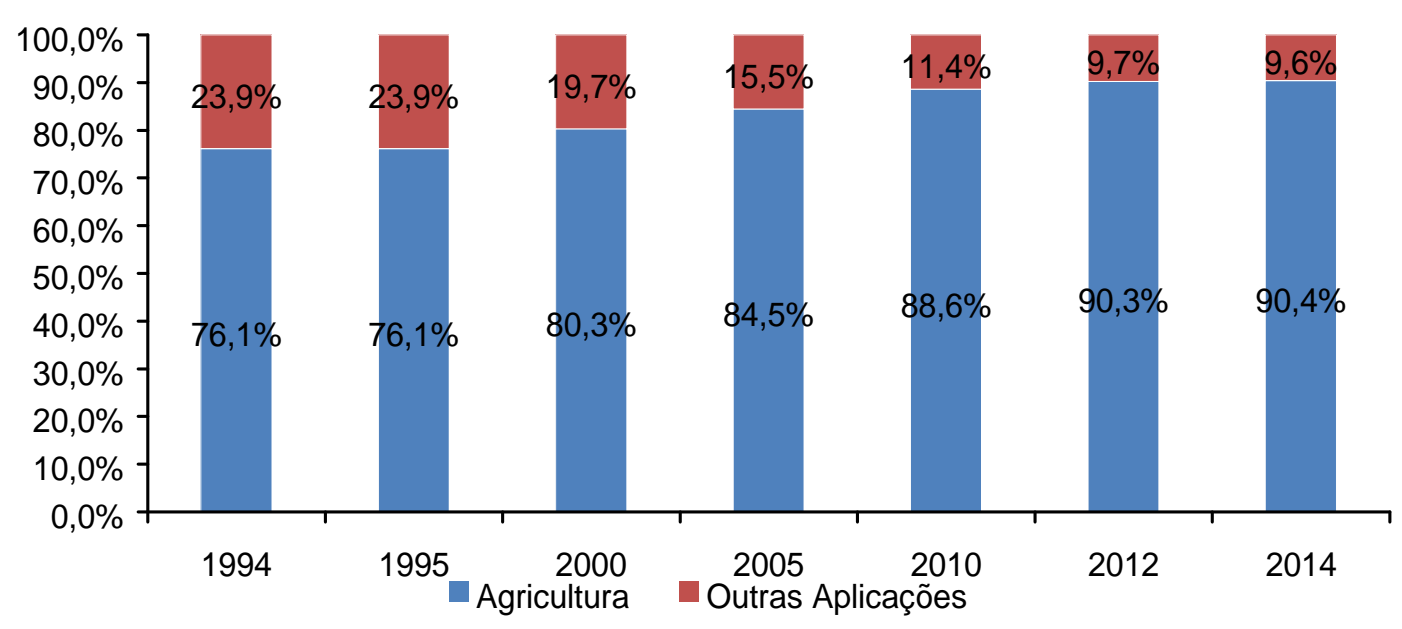

FIGURA 2. Composição do mercado de herbicidas de glifosato de acordo com seu uso.

Fonte: Adaptado de Benbrook (2016)

O glifosato é considerado uma "commodity", devido a padronização e volume comercializado mundialmente, o que faz com que seu preço seja regulado globalmente e sofra flutuações (MARTINELLI JR; WAQUIEL, 2002). A figura 3 mostra a queda no preço ao longo dos anos, juntamente com um crescimento no volume total de glifosato aplicado nas lavouras de soja e milho. 


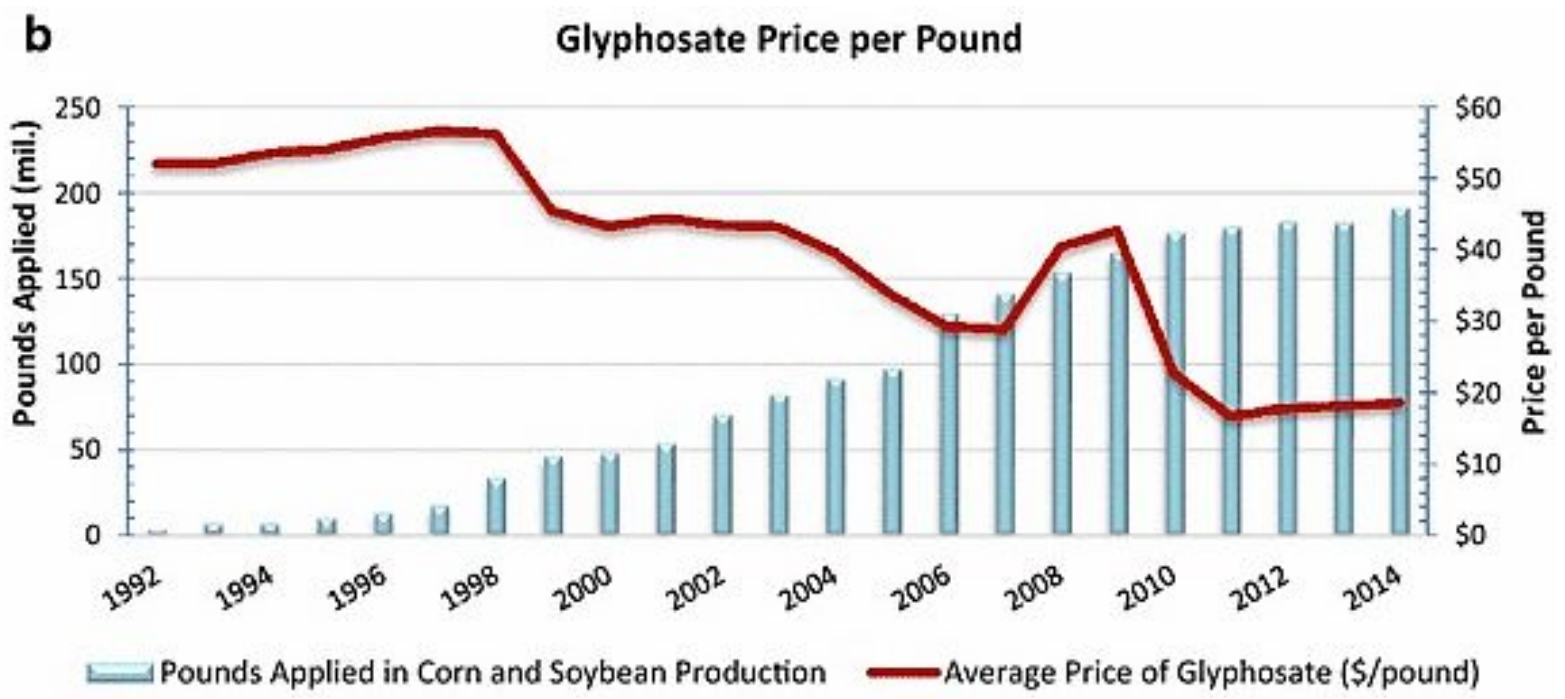

FIGURA 3. Preço em Dólares por libra de glifosato e consumo nas lavouras de milho e soja.

Fonte: Benbrook (2012)

Nota: libras de glifosato na forma de ácido (princípio ativo)

\section{Principais Concorrentes}

Os principais "players" no mercado de glifosato são: Bayer CropScience AG, BASF SE, Syngenta (subsidiária ChemChina), FMC Corporation, Monsanto Company (subsidiária Bayer), E.I. du Pont de Nemours \& Company, Nufarm Limited, Drexel Chemical Company, Arysta LifeScience Corporation, ADAMA Agricultural Solutions Ltd (subsidiária ChemChina), UPL Limited e Heranba Industries Ltd (RESEARCH; MARKETS, 2018).

Desde seu lançamento, o RoundUp® assegura liderança no "market share" dos herbicidas a base de glifosato, mesmo após a queda da patente do ativo em 2000. A empresa adota uma estratégia de preços mais alto do que a média do mercado, por meio da fidelização dos clientes na entrega de soluções completas (defensivo + sementes com genes resistentes), qualidade de seus produtos, financiamento e preços especiais para negociações de alto volume (BENBROOK, 2016).

\section{Teoria de Construção de Preço de Produtos}

Todo e qualquer produto ou serviço oferecido é submetido a um processo de precificação, uma das etapas mais críticas dentro da gestão financeira das empresas. A execução desse processo de maneira adequada garante atratividade, rentabilidade e, consequentemente, sustentabilidade ao negócio, já que de forma antagônica, a determinação errônea do preço pode levar um produto a gerar prejuízos e danos financeiros muitas vezes irreparáveis. Serão exploradas três diferentes estratégias de precificação.

\section{Margem de Contribuição}

Também chamada de precificação, custo somado a margem, é a maneira mais comum de precificação de produtos. A variável a ser definida pela companhia é a taxa de retorno desejada, após ter-se descontado custos e despesas. A análise 
começa com a equação 1 e posteriormente com a equação 2 , chegando-se ao preço de venda unitário (PINDYCK; RUBINFELD, 2009).

$$
C U=C V+\frac{C F}{V}
$$

onde, CU: custo unitário do produto; CV: custo variável; CF: custo fixo; V: valor recolhido com a venda do produto.

$$
P V \equiv \frac{C U}{1-T R}
$$

onde, PV: preço de venda; CU: custo unitário; TR: taxa de retorno desejada.

\section{"Markup"}

Nesse método, o preço final é obtido a partir da composição de custos envolvidos em cada produto, garantindo que além dos custos um determinado nível de lucro seja atingido. Ao final, é obtido um fator que deve ser multiplicado pelo custo total unitário e obtém-se o preço de venda. A equação 3 é utilizada para determinação do fator de "markup" (PINDYCK; RUBINFELD, 2009).

$$
M=\frac{100}{[100-(D V+D F+L P)]}
$$

onde, M: fator de "Markup"; DV: percentual das despesas variáveis; DF: percentual das despesas fixas; LP: percentual do lucro desejado.

\section{Pesquisa de Preço}

A pesquisa de preço consiste em realizar um levantamento dos preços praticados pelos concorrentes diretos do produto ou serviço em questão, se demonstrando muito eficiente quando a empresa quer se manter competitiva no mercado, diante de seus rivais. É importante frisar que esse método é considerado como ponto de partida da precificação, pois ainda deverá será analisado qual o impacto das despesas e custos internos, uma vez que eles deverão ser cobertos a médio/longo prazo para a sustentabilidade do negócio. Essa estratégia está também associada a um mercado com produtos homogêneos, mas onde as empresas podem inserir pequenos diferenciais para justificar um prêmio (incremento) ao preço final (PINDYCK; RUBINFELD, 2009).

Os autores McEwan e Deen (1997) realizaram pesquisa com amostras de empresas produtoras de pesticidas afim de compreender a composição de seus custos, apresentado na figura 4.

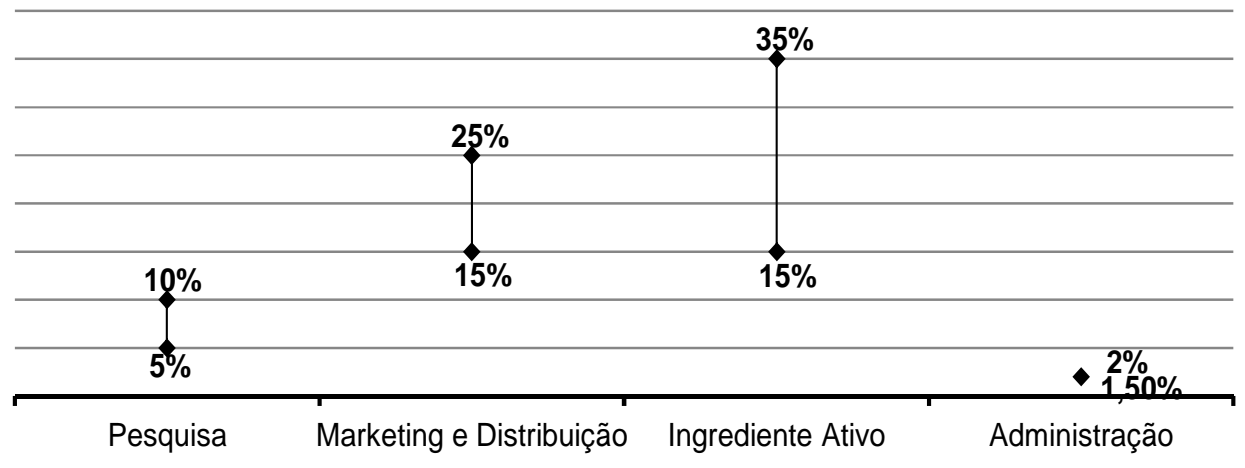

FIGURA 4. Faixa média dos fatores de composição de custos de pesticidas de mercado

Fonte: Adaptado de McEwan e Deen (1997) 
De acordo com o relatório de McEwan e Deen (1997), as empresas de pesticidas trabalham com margens de lucro muito maiores do que o restante da indústria, algo em torno de $40 \%$ de taxa de retorno frente a $15 \%$ praticado por outros segmentos. No relatório, são apresentados três motivos para tais valores:

Nível de serviço oferecido pelas empresas, pois algumas delas são somente revendedoras, já outras se envolvem e tomam os riscos de uma maior parte da cadeia de suprimentos; Diferentes condições de Mercado como tamanho (demanda) e competidores, e outra parte relacionada à aplicação, como facilidade de uso, pragas controladas, tecnologia, etc.; A variação nos custos de produção faz com que as empresas elevem seus preços para poder absorver flutuações de Mercado.

\section{Mapeamento de Fatores de Influência na Formação de Preço}

Para melhor entendimento dos principais fatores de influência na formação de preço do glifosato, mais especificamente no Brasil, foram divididos os fatores em externos e internos, uma vez que a cadeia de suprimento envolve diversos países na cadeia produtiva dos herbicidas. No entanto não se deve assumir que os fatores sejam isolados, mas sim que há uma interdependência entre eles e, ao final, todos têm peso na tomada de decisão das empresas que comercializam os herbicidas a base de glifosato.

\section{Fatores Externos}

\section{- Taxa do Dólar}

O Dólar tem importante papel na determinação do preço no Brasil dos herbicidas a base de glifosato, fato confirmado e citado por diversas vezes durante as entrevistas com os colaboradores da Empresa A. O mercado do glifosato Chinês, pais que é grande fornecedor de ativo, é realizado basicamente em base de dólar, então a variação da moeda causa impacto direto no preço para os importadores no Brasil. Como essa matéria prima tem importante papel na composição dos custos variáveis, consequentemente, o preço final será afetado.

No caso dos fabricantes do ativo no Brasil, o impacto da moeda americana é bastante semelhante. A produção do glifosato é dependente da importação das principais matérias primas, como o fósforo e intermediários químicos que são produzidos a base de petróleo. De maneira semelhante, o petróleo também tem seu preço regulado em dólares, além de ser afetado por aspectos políticos mundiais. Devido a relevância e impacto no preço dos produtos no Brasil, a taxa do dólar é monitorada e acompanhada como um dos principais indicadores da Empresa A.

\section{- Preço do Glifosato Chinês [PRC]}

Dados capturados nos relatórios (RESEARCH; MARKETS, 2018) e nas entrevistas da empresa $A$, reforçam que, após a queda da patente do Glifosato em 2000, a China se mostrou como um importante produtor de glifosato para o mercado global.

Desde o início de sua produção no país, a oferta dentro do país é um fator de importância significativa no preço. Somente em 2005, já eram registradas 17 empresas para produção do glifosato, totalizando uma produção de 180.000 toneladas naquele ano. Três anos depois, o número de competidores subiu para 79, fazendo com que a produção chinesa tivesse um excedente calculado em 600.000 toneladas, continuando a escalada até que em 2010 eram 131 empresas, trazendo o 
valor do glifosato para valores tão baixos quanto o mercado nunca havia experimentado anteriormente (RESEARCH; MARKETS, 2018).

Porém a Comissão Nacional de Desenvolvimento e Reforma da República Popular da China [NDRC], órgão governamental de controle econômico e industrial, incluiu o Glifosato como parte da sua lista de produtos nas quais empresas novas entrantes não são permitidas, restringindo de certa maneira a produção no país e evitando também a criação de capacidade ociosa e queda forçada nos preços.

O sucesso da indústria do glifosato chinês é devido à soma de fatores, como:

O país possui um número significativo de minas de fósforo e plantas produtoras de fósforo amarelo, importante matéria-prima na cadeia produtiva do Glifosato. Hoje é o maior produtor mundial, com cerca de 140 milhões de toneladas produzidas em 2014 (STATISTA, 2018); A indústria petroquímica chinesa é a maior do mundo, responsável 13,2\% do total exportado no mundo em 2017 (Worlds Top Exports. 2018); Incentivo fiscal e governamental, além dos baixos custos de produção e transporte, como apontado nas entrevistas.

Em pesquisa de mercado divulgado pela companhia de pesquisa de mercado China Chemicals Market [CCM], apontou uma tendência de estabilização no preço do glifosato chinês, mostrando que o mercado vem alterando sua orientação, que anteriormente era baseada somente em demanda, e atualmente tem sido influenciado politicamente. A confirmação desse fato foi realizada por meio das entrevistas, onde uma das perguntas questionava a influência política na indústria do Glifosato na China (GUANGZOU CCM, 2016).

Durante a experiência do autor na Empresa $A$, foi possível verificar que sua estratégia utiliza a preço do glifosato chinês como base e que, de acordo com as entrevistas, também é utilizada nos concorrentes da Empresa $A$ como preço base para a comercialização dos herbicidas a base de glifosato.

A estratégia de precificação da Empresa A segue a lógica da pesquisa de mercado, ou também conhecido na indústria como "seguidor de preço", onde os valores apresentados aos clientes são formados com base no preço do glifosato chinês somando-se um valor de "prêmio" ou subtraindo-se um valor chamado de "deságio", conforme as equações abaixo:

$$
\begin{aligned}
& \text { PRC - Deságio = Preço Final } \\
& \text { PRC + Prêmio = Preço Final }
\end{aligned}
$$

onde: PRC ("People's Republic of China"): sigla utilizada para o preço do glifosato chinês na origem e sem custos de frete, utilizado como preço base.

O preço do produto chinês é informação pública, formado a partir dos dados da receita federal, que são abertos, referentes às importações de glifosato (volume importado e preço pago). A aplicação de deságio do preço é basicamente utilizada quando a empresa quer ter maior garantia de que seu produto será competitivo e com valores abaixo da média de mercado.

Composições de preço utilizando-se do prêmio são bastante comuns, porém somas de valores mais altos em casos como a venda de um produto com diferenciais de entrega e serviços, formulações especiais, embalagens específicas, marca do produto, suporte técnico, entre outros atributos que agregam valor. A ferramenta proposta pela Empresa A para dimensionamento do prêmio é a "conjoint analysis". 


\section{- "Conjoint Analysis"}

A "conjoint analysis" é uma técnica de pesquisa de marketing baseada em estatística, na qual atributos de um determinado produto tem sua importância quantificada, ou seja, examina o benefício percebido pelo cliente de cada característica ou vantagem competitiva estudada em relação ao benefício total do produto, assim como frente aos concorrentes (KOTLER; ARMSTRONG, 1995).

A aplicação desse tipo de pesquisa é bastante válida para o mercado do glifosato, uma vez que o produto, como citado anteriormente, possui atributos muito semelhantes entre os concorrentes. Dessa forma, as empresas conseguem dimensionar o tamanho do prêmio que podem impor ao mercado, baseado nas respostas adquiridas nas pesquisas.

Os atributos aplicados na pesquisa da "conjoint analysis" dos herbicidas a base de glifosato são compreendidos, mas não se limitam à: concentração de ativo, impacto da marca, tipo de formulação (seca/líquida), desempenho do produto, entre outros aspectos tangíveis e intangíveis.

Um último ponto considerado, após os resultados da "conjoint analysis" é a elasticidade preço-demanda que é aplicado em um determinado prêmio. A elasticidade do preço é determinada pela razão entre a variação na quantidade de demanda do mercado pelo produto e a variação no preço desse mesmo item (VARIAN, 2006). De acordo com os profissionais entrevistados, essa análise é essencial, pois, por se tratar hoje de um produto semelhante à "commodity", sua margem é baixa então o volume de venda tem um importante papel. Por fim, devese notar que "conjoint analysis" foi considerado fator externo por sua dependência do preço do glifosato chinês, e em determinados casos de produtos já formulados importados para o Brasil.

\section{Fatores Internos}

\section{- Demanda de Mercado e Estoques}

Entre os anos de 1974 e 2014, somente nos EUA, mais de 1,6 bilhões de quilogramas de glifosato, na forma de ingrediente ativo, foram aplicados nas lavouras. Porém, dois terços desse volume foram aplicados somente no período compreendido entre 2004 e 2014 (BENBROOK, 2016). A figura 5 mostra como o crescimento do consumo do glifosato foi exponencial até próximo do ano de 2010.

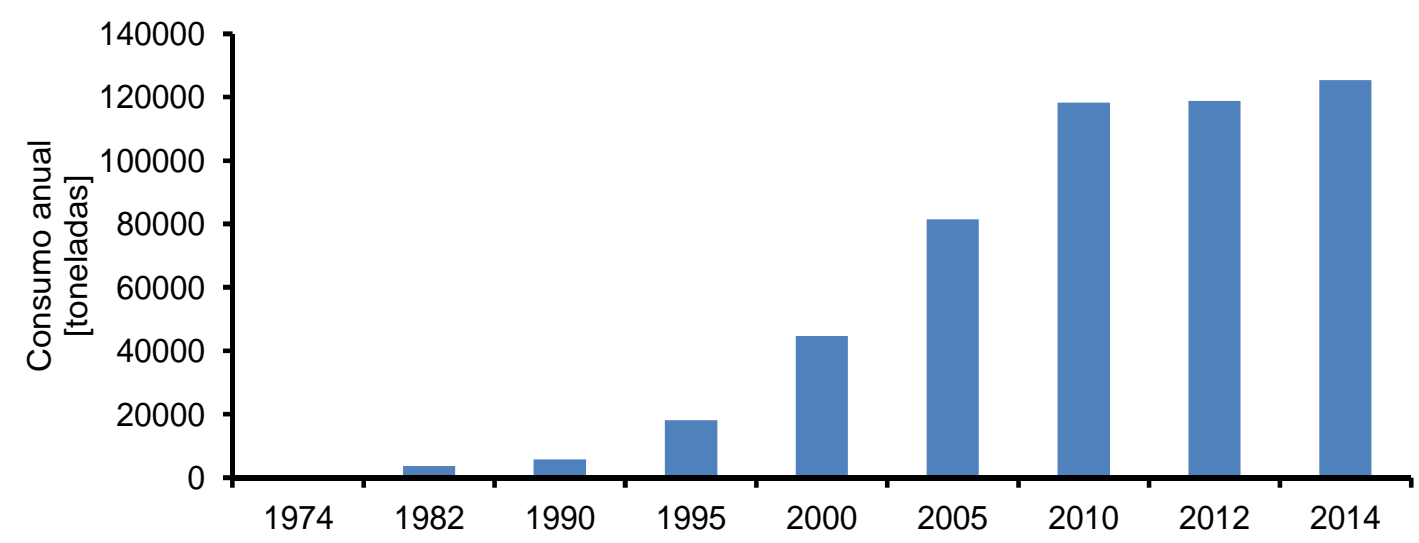

FIGURA 5. Consumo americano de Glifosato ao longo dos anos

Fonte: Adaptado de National Agriculture Statistical Service pesticide use data and the Environmental Protection Agency pesticide industry and use reports (1995, 1997, 1999, 2001, 2007), citado por Benbrook, (2016). 
Hoje a aplicação do produto ocorre de duas formas: como preparação do solo nos períodos de entressafra para limpeza da área e durante a safra, conhecido como aplicação "over the top", que é feita diretamente sobre as plantas, porém, este último com os genes resistentes ao glifosato. Com isso, a demanda do mercado de glifosato segue basicamente os períodos de safra das principais culturas no caso do Brasil, as safras de soja, milho e algodão.

Desta forma, as empresas têm que garantir uma produção de modo que consiga atender os picos de consumo, e conduzirem campanhas de vendas com preços específicos para os períodos de maior demanda. O maior volume de venda é nos meses em que antecede o plantio, onde o agricultor compra praticamente todo o volume que será utilizado naquela safra: de agosto a dezembro para o plantio de milho, soja e algodão (maior demanda) e de janeiro a maio para o plantio de milho safrinha, trigo, aveia e outras culturas de inverno. Os valores de volume de vendas da Empresa A coletados para o presente trabalho e compilados na figura 6, evidenciam os picos de demanda próximos a setembro.

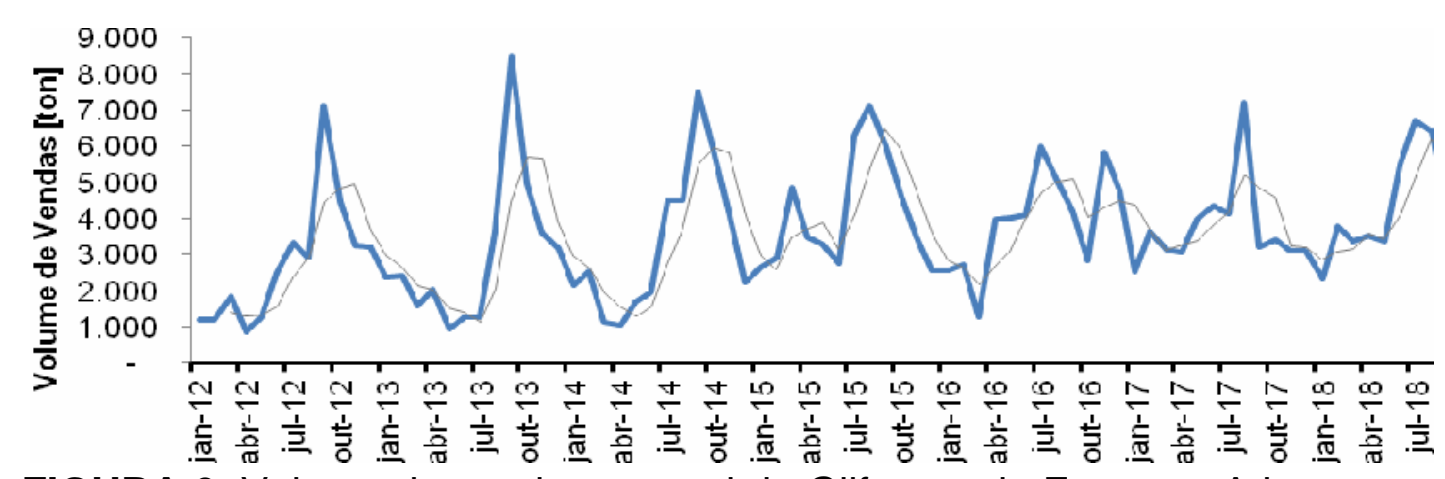

FIGURA 6. Volume de vendas mensal de Glifosato da Empresa A juntamente com a média móvel de três meses.

Fonte: Relatórios internos da Empresa A

Um fator diferencial entra as empresas está no quesito, forma de pagamento, uma vez que o agricultor geralmente paga uma parcela dos insumos no plantio, e o restante é pago após a colheita. As empresas e distribuidores que possuem caixa para oferecer tal flexibilidade, geralmente praticam preços maiores.

Grandes empresas produtoras de ingrediente ativo tem o poder de controlar a produção de maneira mais eficiente, pois controlam a cadeia de fornecimento e possuem a habilidade de reduzir os volumes de produção de acordo com a demanda ou previsão de mercado e safras.

Já as empresas que atuam na ponta da cadeia, somente na formulação e/ou revenda dos herbicidas, e que dependem do glifosato chinês, ficam mais vulneráveis a flutuação de demanda. Isso é explicado, pois o fornecimento é dependente de importação de empresas terceiras, além de trabalharem com estoques maiores, o que aumenta o custo da operação. Como referência do tamanho do mercado e espalhamento entre diferentes concorrentes no Brasil, hoje existe por volta de 120 produtos à base de glifosato registrados (AGROLINK, 2018). 


\section{- Custos de Produção}

No mercado atual dois grandes importantes fornecedores de glifosato são os EUA e China, isso devido à necessidade do fósforo na produção da molécula. Esses produtores hoje trabalham fortemente para aumentar sua capacidade produtiva frente a uma crescente demanda, e da mesma forma uma escassez de matéria prima, o que por vezes gera um aumento nos custos de produção e um aumento global nos preços (AGRICULTURE, 2017).

O mercado brasileiro de glifosato pratica hoje, entre as empresas, análises constantes dos produtos concorrentes. $\mathrm{Na}$ análise, o herbicida passa por uma validação geral, desde composição química do produto até sua embalagem, para que possa ser estimado o custo de produção, transporte e venda. Com base no preço de mercado, é possível estimar a margem da indústria e do distribuidor, chegando a um valor de referência dos custos envolvidos.

\section{- Medidas Protecionistas}

Em 2001, iniciou-se um processo de investigação por parte do Governo Federal brasileiro, sob a condução da Câmara de Comércio Exterior (CAMEX) instalada dentro do Ministério da Indústria, Comercio Exterior e Serviços, avaliando a importação de "glifosato ( $\mathrm{N}$-fosfonometil glicina) importado da China, em todas as suas formas: ácido, sal ou formulado e seus vários graus de concentração, sendo destinado, exclusivamente, à fabricação de herbicida" (BRASIL, 2011).

Como resultado dessa avaliação, em 2003 foi liberada uma primeira resolução que implementou a ação de direito "antidumping" na forma de alíquota ad valorem de $35,8 \%$, o que protegeu o preço do produto comercializado no Brasil contra os baixos valores advindos da China. Tal medida gerou certa controvérsia entre as empresas de agroquímicos, pois sua aplicação protegia os produtores de ativo no Brasil, mas prejudicava a competitividade daqueles que somente realizavam formulação ou comercialização. Como referência, para as empresas fabricantes do ativo, o lucro bruto chegou a cair cerca de $85 \%$ entre o início da entrada dos produtos chineses e o lançamento da primeira medida "antidumping". Até esse momento, a formação de preço era feita conforme a estratégia de margem de contribuição, também chamada de "Cost Plus", onde as margens de lucro são impostas para o mercado.

A alíquota estabelecida foi sendo revisada constantemente nos anos seguintes, até que por meio da Circular № 22 de 18/05/11 (BRASIL, 2011), foi lançado o cálculo definitivo da ação de "antidumping" vigente até hoje, que estabelece as alíquotas, para o valor do glifosato no destino, como definido a seguir pelas equações 6 e 7 como valores em dólares por quilograma.

Direito Antidumping Específico (DAE) para glifosato ácido 95\%

$D A E=U \$ 3,60$ por $\mathrm{kg}-$ Preço por $\mathrm{kg}$ ấcido de cada operação de importaçã̃o

Direito Antidumping Específico (DAE) para glifosato formulado ou sal

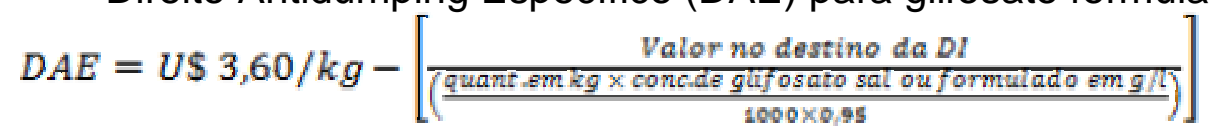

onde, DI: Declaração de Importação; quant.: quantidade; conc.: concentração.

\section{CONCLUSÃO}

Os fatores como, taxa do dólar, preço do glifosato chinês, demanda de mercado e as intervenções do governo não podem ser facilmente gerenciados pelas empresas, mas uma parte dos custos de produção e as características do seu 
produto, que impactam positivamente na "conjoint analysis", são fatores que devem receber a maior concentração de esforços das empresas para maximizarem seus lucros com a venda dos herbicidas à base de glifosato.

\section{REFERÊNCIAS}

AGRICULTURE. What's behind glyphosate and Roundup prices hikes? 2017. Disponível em: <https://www.agriculture.com/news/bisiness/WHATS-BEHINDGLYPHOSATE-AND-ROUNDUP-PRICE-HIKES_5-AR3742>. Acesso em: 09 de novembro de 2017.

BENBROOK, C. M. Trends in glyphosate herbicide use in the United States and globally. Environmental Sciences Europe. v.28, n.3. 2016. Disponível em: https://doi.org/10.1186/s12302-016-0070-0.

BUSINESSWIRE. Global Glyphosate Market 2017-2021: Segmentation by Application \& Type - Research and Markets. Disponível em: https://www.businesswire.com/news/home/20170921005509/en/Global-GlyphosateMarket-2017-2021-Segmentation-Application-Type. Acesso em: 11 de novembro de 2017.

GALLI, A.; MONTEZUMA, M. Alguns Aspectos da Utilização do Herbicida Glifosato na Agricultura. São Paulo: ACADCOM Gráfica e Editora Ltda. 2005.

GUANGZHOU CCM INFORMATION SCIENCE \& TECHNOLOGY [CCM]. CCM: Review of China's 2015 glyphosate market. 2016. Disponível em: http://www.cnchemicals.com/Press/84080-

CCM:\%20Review\%20of\%20China\%E2\%80\%99s\%202015\%20glyphosate\%20marke t\%20(I).html. Acesso em: 11 de agosto de 2018.

IMEA - Instituto Mato-grossense de economia agropecuária. 2018. Custos de produção de soja - Safra 2017/2018. Disponível em: http://www.imea.com.br/upload/publicacoes/arquivos/21112016171539.pdf. Acesso em: 11 de agosto de 2018.

KOTLER, P.; ARMSTRONG, G. Princípios de marketing. tradução de: Vera Whately. 7. ed. Rio de Janeiro: LTC, 527p. 1995.

MARKETS AND MARKETS. Glyphosate Market by Crop Type (Genetically Modified, Conventional), Form (Liquid, Dry), Application (Agricultural (Grains \& Cereals, Oilseeds \& Pulses, Fruits \& Vegetables), Non-Agricultural), and Region - Global Forecast to 2022. 2017. Disponível em: https://www.marketsandmarkets.com/Market-Reports/glyphosate-market8522593.html. . Acesso em: 18 de janeiro de 2019.

MARTINELLI JR, O.; WAQUIEL, P.D. Tendências recentes na industria de defensivos agrícolas no Brasil. Análise Econômica. ano 19, n. 36. p.123-142. 2002.

MCEWAN, K.; DEEN, B. A. Review of Agricultural Pesticide Pricing and Availability in Canada. 1997. Disponível em: http://www.agr.gc.ca/spb/fiapdpraa/publications/pesticide/pest_toc_e.php. Acesso em: 18 de janeiro de 2019. 
BRASIL, Ministério do desenvolvimento, indústria e comércio exterior/câmara de comércio exterior [MDIC/SECEX/CAMEX]. Dispõe sobre direito antidumping aplicado às importações de glifosato ( $\mathrm{N}$-fosfonometil glicina) em todas as suas formas (ácido, sais e formulado) e graus de concentração, destinado, exclusivamente, à fabricação de herbicida. Circular $\mathrm{n}^{\circ} 22,2011$. Disponível em: http://www.mdic.gov.br/arquivos/dwnl_1305818178.pdf. Acesso em: 07 de agosto de 2018.

OECD-FAO - Food and Agriculture Organization of the united nations [FAO] 2018. Agricultural Outlook 2018-2027. Disponível em: http://www.fao.org/3/i9166en/l9166EN.pdf. Acesso em: 11 de agosto de 2018

ONU - organização das nações unidas [ONU]. World Population Prospects. 2017. Disponível em: https://esa.un.org/unpd/wpp/Publications/Files/WPP2017_KeyFindings.pdf. Acesso em: 04 de agosto de 2018.

PINDYCK, R. S.; RUBINFELD, D. L. Microeconomics. New Jersey: Pearson/Prentice Hall. 2009.

RESEARCH AND MARKETS. Glyphosate Market - Global Opportunity Analysis and Industry Forecast (2017-2022). 2017. Disponível em: https://www.researchandmarkets.com/reports/4418859/glyphosate-market-globalopportunity-analysis. Acesso em: 12 de fevereiro de 2018,

STATISTA. Production of phosphate in China from 1960 to 2015 (in million tons). 2018. Disponivel em: https://www.statista.com/statistics/307480/chinaphosphate-production/. Acesso em: 28 de setembro de 2018.

SUSTAINABLE PULSE. A Short History of Glyphosate. 2017. de https://sustainablepulse.com/2017/09/06/a-short-history-of-glyphosate. Acesso em: 04 de agosto de 2018

VARIAN, H. (2006). Microeconomia: Princípios Básicos. Rio de Janeiro: Elsevier, 7ed. 2006

WORLD'S TOP EXPORTS [WTEX]. (2018). Chemical Exports by country. 2018. Disponível em: de http://www.worldstopexports.com/chemical-exports-by-country/. Acesso em: 05 de agosto de 2018. 